\title{
Metropolitan Growth: Sun Belt vs. Snow Belt
}

\author{
Rubén Hernández-Murillo
}

$\mathbf{F}$ or more than a century, cities in the United States with more skilled residents have grown faster than comparable cities with fewer educated people. ${ }^{1}$ The reasons why the relationship between skills and population growth is so persistent are not clearly understood. One explanation proposes that skills (measured by the percentage of residents with a bachelor's degree) foster growth because an educated population is an indicator of favorable quality of life, which attracts more people to a city. An alternative explanation argues that having skilled residents allows cities to grow because educated people adapt more easily to a constantly evolving economy. The latter explanation views skills as a production amenity, whereas the first views skills as a consumption amenity.

Recent evidence suggests that productivity drives most of the connection between skills and growth, especially in metropolitan areas, supporting the production amenity explanation. Economists Edward Glaeser and Albert Saiz have found that education levels have a positive impact on the growth of wages and housing prices, as a result of rising productivity. If skills are merely consumption amenities, they argue, then wages would decline following migration to a city. ${ }^{2}$

Interestingly, the relationship between skills and city growth does not hold among all types of cities. In the latter part of the 20th century, cities with warm and dry climates have dominated the list of the fastest growing metropolitan areas, in terms of both population and employment growth. ${ }^{3} \mathrm{~A}$ favorable climate, especially since the advent of air conditioning, seems to have spurred growth in such areas without relying on a high level of education in the local population. The correlation between skills and growth, however, seems to be more important in cold and wet metropolitan areas (the Snow Belt) than in warm and dry locations (the Sun Belt).

The chart presents the correlation between the fraction of residents aged 25 years or older with college degrees as of 1990 and population growth in 155 Snow Belt metropolitan areas over the 1990-2000 decade. The correlation between skills and population growth is 0.52 and the relationship is statistically significant. The line of best fit in the chart suggests that, as the fraction of people with bachelor's degrees increases by 1 percent, population growth in the following decade increases by 1.2 percent. A similar exercise among Sun Belt metropolitan areas

reveals no significant correlation between skill levels and subsequent population growth, perhaps, in part, because the Sun Belt receives a disproportionate share of the immigrant population. The same pattern arises if, instead of population growth, one examines employment growth, as measured by the change in the number of employed civilians aged 16 years or older. The correlation between employment growth in the 1990s in Snow Belt metropolitan areas and the initial level of skills is 0.39 , whereas the correlation is only 0.03 in Sun Belt metropolitan areas.

One caveat-which we can call the Las Vegas explanationis that relatively low-skilled service workers comprise a large share of a Sun Belt metropolitan area's permanent population, even though the share of college-educated people in the city at any given time-including tourists and snowbirds-may be actually quite high.

\footnotetext{
${ }^{1}$ Glaeser, Edward L. "Why Does Schooling Generate Economic Growth?" Economics Letters, 1994, 44(3), pp. 333-37.

${ }^{2}$ Glaeser, Edward L. and Saiz, Albert. "The Rise of the Skilled City." NBER Working Paper No. 10191, National Bureau of Economic Research, 2003.

${ }^{3}$ Bureau of Labor Statistics. "Warm Areas Continue Hottest Job Growth." Issues in Labor Statistics, May 1997.
}

\section{Population Growth in Cold MSAs \\ (Average January Temperature under $40^{\circ} \mathrm{F}$ in 1961-90)}

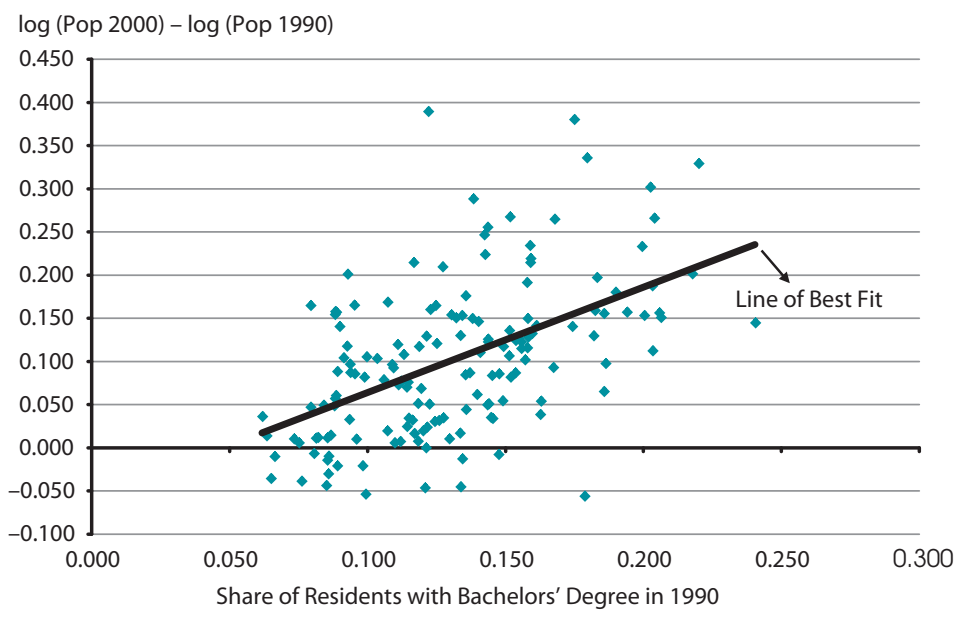

NOTE: Data are from the U.S. Census Bureau. 